\title{
Knowledge Economy and Regional Innovation Policy Milieu
}

\author{
M. Patrizia Vittoria ${ }^{1, a}$, Pasquale Persico ${ }^{2, b}$ \\ ${ }^{1}$ Institute for Service Industry Research (IRAT), National Research Council (CNR), Naples, ITALY \\ ${ }^{2}$ Department of Economics and Statistics (DISES), University of Salerno, Salerno, ITALY \\ am.vittoria@irat.cnr.it, ${ }^{b}$ ppersico@unisa.it
}

\begin{abstract}
Keywords: Knowledge Economy, Regional Innovation Policy, Social Network Analysis, Dynamic Capabilities.
\end{abstract}

\begin{abstract}
The emergence of the knowledge economy has resulted in a new definition of regional policy milieu. Under the current EU policy framework the concepts of region and city are the result of an inductive, exploratory cognitive process. Interpreting, assessing and designing successful territorial milieux constitute a methodological challenge for analysts. This paper discusses the methodological capacity of a hybrid theoretical approach to discovery and design of smart specialization. Analysis of strategic network formation (why the network takes a particular form) demonstrates the competitive positioning of specific homogeneous communities within the global value chain and can be considered central to the regional policy milieu.
\end{abstract}

\section{Introduction}

Regional policy rationales generally are underpinned by the idea of local development. Thus, in the economic literature on industry clusters - starting from Marshall's (1920) contribution on localization economies - policy milieux are described by concepts such as industrial districts [1, 2], clusters [3], innovative milieux [4], regional innovation systems [5], learning regions [6] and agglomerated urban environments $[7,8]$.

A new definition of regional milieu, inspired by the notion of the 'knowledge economy', is emerging within the recent regional innovation policy framework. This notion gives to knowledge a particular strategic meaning. It considers wealth creation to be based less on the accumulation of scarce resources than on the (strategic) valorization of new knowledge. The policy is aimed at achieving regional excellence through the build-up of local strategic intelligence for knowledge creation and valorization $[9,10]$.

However, it should be noted that theories about how to foster regional development in the 'knowledge-based economy' differ. The various modes of knowledge transfer and diffusion, and analyses of 'how to govern' the set of heterogeneous codified and tacit knowledge, are crucial issues for economic growth [11]. The regional dimension to these problems, and the implications for local competitiveness (due, e.g., to the global scale of the market for knowledge assets) are widely discussed.

We start by considering that the basic mission of regional policy is to assist regional development, and that regional development depends on the efficient (strategic) management of knowledge relationships [13, 14]. To manage knowledge relationships strategically is a crucial individual and organizational capability, especially in the science-based industries [15]. The ability to choose a knowledge partner is a capability that needs to be extended to the larger scale, and a central scientific concern for policy makers is to define organizational competitive positioning (and the effective distance among the involved actors) in the international knowledge networks.

Beyond the major scientific dispute between knowledge distinctiveness and the importance of 'the skilful combination of knowledge' for competitive advantage, there are many other problems that have emerged in the context of lagging regions. It is well-known that peripheral regions generally have a lower capacity to absorb even publicly available knowledge despite their crucial 
need for new knowledge. This is described as the innovation paradox [12] and refers to the small capacity of peripheral regions to obtain public funding for regional innovation support. In these circumstances, a major empirical concern is related to the definition of a specific area as the target for policy.

The present paper proposes a model to identify and map Knowledge Networks (KNs) as the main context for the knowledge interactions emerging from the strategic partner selection process. Strategic analysis of localized KNs can be considered decisive for setting the regional policy milieu. Analysis of the network structure can be used to orient the process of policy making.

The next two sections present the main theoretical foundations of a model in which the research process related to 'discovery' of the regional policy milieu is an inductive and exploratory cognitive process, and provide a brief discussion of the multi-scale nature of territorial governance in which the model efficiently reconnects the core and periphery areas through the wider spatial network. Reference will be made to empirical evidence from previous case studies.

\section{Regional development based on knowledge network capabilities}

One of the most recent and exhaustive studies of regional development and the increasing role of regional knowledge capabilities uses longitudinal findings from specific technological fields, particularly (but not only) biotechnologies [16]. The analysis, which draws on work in geography, reveals a knowledge driven regional development evolution which the authors call Globalization 2 . The present paper contributes to this stream of work. We investigate the type of regional development that would best fit with the current regional policy approach. We exploit Dynamic Capabilities theory (DC) and Social Network Analysis (SNA) which we apply in the empirical analysis to the specific case of the Campania bio-community.

Following Penrose's (1959) contribution and interpretations by Teece et al. [17, 18], the DCs framework has been used to analyse how private enterprises create wealth in environments characterized by rapid technological change. These firm-level studies consider knowledge as the most important resource, and organization as the key variable related to the achievement of competitive advantage. From this theoretical framework emerged the concept of knowledge network capabilities, which refer to micro-, meso-, and macro-level relational abilities to channel knowledge and information for value creation.

Parallel empirical analysis of Knowledge Networks (KNs), at both firm and regional levels, assesses the existence and spatial extent of knowledge flows, that is, the network links. Following early work on the knowledge production function (an approach that assumes a positive correlation between regional innovative inputs and outputs as evidence of localized knowledge spillovers), several studies have focused on direct measures of knowledge flows. This work shifts the unit of analysis from the regional to the individual innovation or individual researcher level, using patent citations [19], mobility of skilled workers [20], market and non-market relationships in the dimension of proximity [21], and social networks [22]. Our approach adopts strategic models of social network formation [23], and links explanations to fundamental aspects of the settings. For example, combining of high clustering with small diameter (i.e. largest distance between any two network nodes) comes from a strategic analysis that relates high levels of clustering to low costs for connecting nodes that are socially or geographically close, and small diameter to the benefits of accessing information held by distant nodes. In situations where information diffuses through the network, agent payoffs depend on their access to this information, which shapes their incentives regarding which relationships to form or maintain, and ultimately affects the network structure.

The case of the Campania bio-community has been observed along the lines of a firm-level management model (how private enterprises create wealth in environments characterized by rapid technological change) and strategic models of social network formation. In the observed community, we search for organizational solutions to knowledge management for competitive 
advantage. The empirical analysis is conducted in two phases. ${ }^{1}$ Since social relational modes (forms and motivations) depend on the local institutional context and how the local actors self-organize to construct their strategic responses, the first phase consists of a micro analytical survey. It explores what types of social relations are more likely to transmit relevant knowledge. The second phase, the macro analytical survey, analyses the relational categories emerging from the first phase to provide a whole-network overview. ${ }^{2}$ The $\mathrm{KN}$ visualizations describe the local bio-community. Evidence at this level shows the most frequent interactions between the local public research organizations (PRO) and their counterparts across the word. The advantages of reciprocal relationships are knowledge integration and funding. Also, in a few cases, some private sector partnerships lead to technological platforms and research collaborations. PRO relationships are formal, but temporary and allow participation in international research networks; the latter are more stable equity participations. During the period of the research, the actors that achieved the most central positions were those that represented the highest value in the local bio-community. The adoption of specific relational connections (e.g., participation in publicly funded research projects rather than more structured partnerships) reveals the dominant strategic behaviour of the most critical sub-groups in the bio-community.

Our network-based view of the local bio-community shows the distribution of relational abilities. Within this field (and according to our research hypothesis) those actors that are linked to the international research community survive. Survival (a dynamic indicator of firm performance) requires the capacity to absorb external knowledge and to access public funding.

In our view, this representation of the regional bio-community illustrates the effective distribution of innovation capacities among local actors. Analysis of the forms and motivations of regional social relationships for knowledge exchange is crucial for understanding the partnering selection criteria adopted. In turn, these criteria reveal local capacity to include external relationships.

Analysis of the network structure and node positions reveals the role played by specific actors within the regional community. Investigating the weight of particular nodes in terms of linkage density and positioning (central or marginal) is important to understand the effective spatial dimension of the community. Of course, the definition of network boundaries is marked by the nature (form and motivation) of the links.

Thus, the analysis adopts the concept of regional development focused on the role of knowledge network capabilities, which refer to micro-, meso-, and macro-level relational abilities to channel knowledge and information for value creation. This perspective on the configuration of the Campania bio-community reveals its weaknesses (poorly connected or isolated local industry from distributed partners) and strengths (a few, excellent internationally connected scientists). At policy level, scientific debate over the choice between specialization and diversification [27, 28] as the development pattern is overtaken by the idea of strategic search for better positioning of a regioncity-community within the global knowledge value chain. The strategic pattern promotes decision making at the micro and macro levels.

Finally, we investigate how this concept of regional development could function better within the current regional policy approach. Current regional policy emphasizes that only a small number of regions can be at the research and innovation frontiers. Regions have to position themselves within the wider knowledge economy. The role of policy increasingly is shaped by the corresponding recipient territorial context. 'Leading' regions are those that primarily engage in valorisation of new, frontier technology, and 'follower' regions are those that search for specific combinations and

\footnotetext{
${ }^{1}$ The research is based on specific case studies of research-based bio-organizations [24]. The data collection technique used is SNA [25]. The first research step is a firm level interpretative case study to identify the relational modes that enable the accumulation of knowledge value in specific organizational settings. For each case, we apply an ego-centric [26] network study by setting the network borders during data collection.

${ }^{2}$ The second step is a whole-network level case study in which the most critical relationships that emerged from the first step of the analysis are used to analyze the whole regional biotech community.
} 
applications in response to market opportunities. This differentiation should be accompanied by an 'unbounded view' of the regional economy that pays attention to the critical role of external economic and research linkages, and the position of the region in global value chains.

\section{Metropolitan areas and the multi-scale capacity of territorial governance}

As referred to above, the innovation paradox in relation to peripheral regions highlights the contradiction between the comparatively greater need to spend on innovation and the relatively lower capacity to absorb public funds for the promotion of innovation and to invest in innovation related activities, compared to more advanced regions [12]. In the Campania bio-community what is needed is policy oriented to supporting smart organizations represented by the local basic research organizations mostly public or non-profit. This kind of policy differs from previous public intervention which focused on the creation of innovation intermediaries (competence centres) aimed to create links among local poles of basic research and potential applicants in the region. This would represent a radical change in public policy to respond to needs, but would go some way to resolving the innovation paradox.

Since the early 2000s, EU policies have focused on research and innovation and, in particular, on the emergence of regional biotechnology clusters. The initial phase (2000-2006) supported the creation of new actors - competence centres - to become innovation intermediaries, address deficiencies in the regional innovation system, and strengthen the connections between public research and local business. The development strategy implemented during 2007-2013 shows important differences from the previous policy and focuses on maintaining and complementing existing learning capabilities and expertise. A selective mechanism is included so that the possibility to access public funding depends on the presence in the region of excellence and learning capabilities.

The Campania biotechnology pole and its few, but excellent, research centres, can be considered as showing effective and localized innovation potential. Among Campania's academic institutions, including the University of Naples which has the longest established Faculty of Biology in Italy, the region hosts an important scientific pole comprising prime biomedical research entities (the Institute of Genetics and Biophysics "Adriano Buzzati-Traverso", the Institute of Protein Biochemistry of the National Research Council (IGB/CNR) and the Telethon Institute of Genetics and Medicine (TIGEM)) which contribute to making the area attractive to biomedical researchers and young scientists seeking training. The Stazione Zoologica Anton Dohrn in Campania is a world leading research centre in marine biology and ecology. However, the industry structure in this field is less developed, with only a few dedicated biotechnological firms (13 in 2013), and low levels of innovation in more populous adjacent sectors (agro-food, pharmaceuticals and diagnostics).

Emerging networks show that biotechnology competence is diffused across the regional territory and demonstrates how the core and periphery of the local research industry network produces value.

The failure of the local development approach to respond to urban needs has led to the concept of metropolitan area in regional policy, as an attempt to extend city borders. The idea of vast area implies multi-scale capacity of territorial governance that includes resolution of or bypassing of current urban institutional rules/constraints on urban spaces. Recent research on smart specialization -mainly using a network approach - reveals bundles of smart activities on different competitive and technological scales within cities [29]. This new network level requires multilevel governance. This relational approach is aligned to possible new responses to the innovation paradox, namely changes to the spatial governance structures [30].

The network approach is useful for understanding the new challenge for regional innovation policy: the co-existence of social and technical innovation policy. Social policy refers to public interventions aimed at citizen learning. Technical innovation policy refers to localized technology transfer for value creation and territorial valorization. In the context of the EU, the problem of division of responsibility among spatial levels (implied by the EU principle of subsidiarity) in the 
division and alignment of tasks [14] is growing. In this context, regional innovation policy is integral to a multilevel governance approach to innovation [31]: 'Instead of seeing regions as a kind of generic laboratories producing "best practices" for the community at a large, regional innovation initiatives should become strategically tied to specific (combinatory) research and innovation networks and programmes at (inter)national levels. The consequence is that smart specialization in research networks and value chains should be accompanied by smart specialization in governance' [31, p. 606].

\section{Conclusion}

This paper presents a discussion of a methodological model adopted for a previous in-depth empirical analysis of bio-communities located in a lagging region of the EU. The discussion focused on issues related to the problems of interpreting, assessing, and designing a successful territorial milieu under current regional policy.

The paper was organized in two sections corresponding to the central analytical concern: exploration (i.e. 'interpreting and assessing' as referred to above) a successful territorial milieu, and its exploitation (i.e. 'designing').

The first section argued for the appropriateness of a hybrid approach to the exploration of smart specialization. We proposed a DCs view linked to SNA to explore the distribution of knowledge network capabilities in a specific bio-community. This revealed localized smart specialization and effective value of localized KNs based on inductive and exploratory cognitive analysis. Following our model, the empirical survey moved from the micro to the macro analytical dimensions. Integration between the two components was enabled by SNA.

The second section reflects on which model of territorial governance best fits this kind of surveys. We considered that the adoption of a hybrid methodological approach to explore smart specialization implies the need for multi-scale territorial governance. The urban dimension (and the regional one) adopts a wide scale. Current urban pathologies, which are intertwined and complex, require substantial mutation. Policy maker have to become more able to effectively interpret the meaning of localized collaboration and the different advantages connected to physical and cognitive distances among the actors observed. Bridging between two actors in an economic context could correspond to integrating different resources.

The sum of the buildings and/or sustainable places in an urban area is not the same as the 'landscape ecology'. A 'smart city' network must be contextualized to the degree of territorial competitiveness at which most network processes occur.

Finally, the proposed model allows a better understanding of the effective value of a regional biocommunity and could contribute to resolving the 'innovation paradox'.

\section{Summary}

Under the new scientific paradigm of the knowledge economy many problems have emerged related to defining the borders of regional policy recipient areas. Network analysis can be used as a tool for evaluating important aspects of system efficiency, and to explore and exploit the emergent regional policy milieu. The analysis follows the idea that regional development depends on the strategic distribution of knowledge network capabilities. These capabilities have been examined in economic geography at macro-level and are shown to create and exploit asymmetric knowledge endowments.

\section{Acknowledgements}

This research was developed within the framework of the EU REPOS project "Reti, Politiche pubbliche e Sviluppo (Networks, Public Policies and Development)", POR Campania FSE 20072013, following seminal work by Prof. P. Persico. 


\section{References}

[1] G. Becattini: The Marshallian industrial district as socio-economic notion, in: F. Pyke, G. Becattini, W. Sengenberger (Eds.), Industrial districts and inter-firm co-operation in Italy, International Institute for Labour Studies (ILO), Geneva (1990), pp. 37-51

[2] S. Brusco: The idea of the industrial district: its genesis, in: F. Pyke, G. Becattini, W. Sengenberger (Eds.), Industrial districts and inter-firm co-operation in Italy, International Institute for Labour Studies (ILO), Geneva (1990), pp. 10-19

[3] M. E. Porter: The Competitive advantage of nations, MacMillan, London (1990)

[4] R. Camagni: Innovation networks: spatial perspectives, Belhaven, London (1991)

[5] P. Cooke: Regional innovation systems, clusters, and the knowledge economy, Industrial and Corporate Change 10:4 (2001), pp. 945-974

[6] B. Asheim: Industrial districts as 'learning regions': a conditions for prosperity, European Planning Studies 4:4 (1996), pp. 379-400

[7] D. B. Audretsch: Agglomeration and the location of innovative activity, Oxford Review of Economic Policy 14 (1998), pp. 18-29

[8] Z. J. Acs: Innovation and the growth of cities, Edward Elgar, London (2002)

[9] Innovating Regions in Europe (IRE), Mutual learning platform, Synthesis Report, Luxembourg (2006)

[10] European Commission (EC), Good practice in the field of regional policy and obstacles to the use of the structural funds, Brussels, Commission of the European Communities. DirectorateGeneral for Regional Policy, Policy Department Structural and Cohesion Policies 2008

[11] J. B. Barney, W. Hesterly: Organizational economics: understanding the relationship between organizations and economic analysis, in: S. Clegg and C. Hardy (Eds.), Studying Organization: Theory and Method, Sage Publications, London, 1999, pp. 111-48

[12] C. Oughton, M. Landabaso, K. Morgan: The regional innovation paradox: innovation policy and industrial policy, Journal of Technology Transfer 27 (2002), pp. 97-110

[13] D. Foray, Globalization of R\&D: linking better the European economy to "foreign" sources of knowledge and making EU a more attractive place for R\&D investment, Brussels: European Commission 2006

[14] L. Soete, The role of community research policy in the knowledge-based economy. Expert Group Report, Brussels: European Commission, Directorate-General for Research 2009.

[15] A. L. Olivier, J. P. Liebeskind: Three levels of networking for sourcing intellectual capital in biotechnology: implications for studying inter-organizational networks, International Studies of Management \& Organization, 27 (1998), pp. 76-104

[16] P. Cooke: Regionally asymmetric knowledge capabilities and open innovation. Exploring 'Globalization 2' - A new model of industry organization, Research Policy, 34 (2005) 11281149

[17] D. J. Teece, G. Pisano, A. Schuen: Dynamic Capabilities and Strategic Management, Strategic Management Journal, 18: 7 (1997), pp. 509-533.

[18] D.J. Teece: Explicating dynamic capabilities: the nature and microfoundations of (sustainable) enterprise performance. Strategic Management Journal, 28:13 (2007), pp. 1319-1350

[19] A.B. Jaffe, M. Trajtenberg, R. Henderson: Geographic localization of knowledge spillovers as evidenced by patent citations, Quarterly Journal of Economics, 108:3 (1993), pp. 577-598

[20] P. Almeida, B. Kogut: Localization of knowledge and the mobility of engineers in regional networks, Management Science, 45:7 (1999), pp. 905-917

[21] R. Boschma: Proximity and innovation: a critical assessment, Regional Studies, 39:1 (2005), pp. 61-74

[22] A. Agrawal, I. Cockburn, J. McHale: Gone but not forgotten: knowledge flows, labour mobility, and enduring social relationships, Journal of Economic Geography, 6:5 (2006), pp. 571-591 
[23] M. O. Jackson, Y. Zenou (Eds): Economic analyses of social networks, Elgar Research Collection, Cheltenham, UK, Northampton, MA, USA (2013)

[24] M. P.Vittoria, G. Lubrano Lavadera: Knowledge networks as the nouvel milieu of biotechnology firms in peripheral regions. Paper presented at 35th DRUID Celebration Conference 2013, Barcelona, Spain, June 17-19

[25] J. Scott, P. J. Carrington (Eds.): The SAGE handbook of social network analysis. SAGE, London (2011)

[26] P. V. Marsden: Recent development in network measurement, in: P.J. Carrington, J. Scott, S. Wasserman (Eds.), Models and Methods in Social Network Analysis, Cambridge University Press, New York, (2005), pp. 8-30

[27] E. Glaeser, H. Kallall, J. Scheinkman, A. Shleifer: Growth in cities, Journal of Political Economy, 100 (1992) pp. 1126-1152

[28] M. Feldman, D. Audretsch: Innovation in cities: science-based diversity, specialization and localized competition, European Economic Review, 43 (1999), pp.409-429

[29] P. Persico: La città e l'altra città. Racconti ed esperienze in-disciplinate nella pianificazione anti-fragile. Palazzo Bonaretti editore srl, Novellara (RE) (2013)

[30] S. Kuhlmann: Future governance of innovation policy in Europe - three scenarios, Research Policy, 30 (2001), pp. 953-976

[31] A. Lagendijk: Regional innovation policy between theory and practice, in: P. Cooke with Bjørn Asheim, R. Boschma, R. Martin, D. Swartz, and F. Tödtling (Eds.), Handbook of Regional Innovation and Growth, EE, Cheltenham, UK, Northampton, MA, USA, (2011), pp.597-608 